\title{
CORRECTION
}

\section{Correction to: Measuring phase scintillation at different frequencies with conventional GNSS receivers operating at $1 \mathrm{~Hz}$}

\author{
Viet Khoi Nguyen ${ }^{1,2}$ (D) Adria Rovira-Garcia ${ }^{1}$ José Miguel Juan ${ }^{1} \cdot$ Jaume Sanz ${ }^{1}$. Guillermo González-Casado ${ }^{1}$. \\ The Vinh $\mathrm{La}^{2}$. Tung Hai Ta
}

Published online: 10 January 2020

๑) Springer-Verlag GmbH Germany, part of Springer Nature 2020

Correction to: Journal of Geodesy (2019) 93:1985-2001 https://doi.org/10.1007/s00190-019-01297-z

In the version of the article originally published, Eqs. (2), (3), (10) and (20) were shown incorrectly. The corrected equations are the following:

$\sigma_{\varphi_{f}}=\sqrt{\left\langle\varphi_{f}^{2}\right\rangle-\left\langle\varphi_{f}\right\rangle^{2}}$

$\sigma_{\hat{\emptyset}_{f}}=\sqrt{\left\langle\hat{\emptyset}_{f}^{2}\right\rangle-\left\langle\hat{\emptyset}_{f}\right\rangle^{2}}$

$$
M(\alpha)=1 / \sqrt{1-\left(\frac{R_{E}}{R_{E}+h} \cos (\alpha)\right)^{2}}
$$

$$
\sigma_{\emptyset_{f}}=\sqrt{\left\langle\emptyset_{f}^{2}\right\rangle-\left\langle\emptyset_{f}\right\rangle^{2}}
$$

These corrections do not affect any of the results or other expressions in the paper. We are grateful to Dr. Adria Rovira-Garcia for pointing out the above errors.

1 Research Group of Astronomy and Geomatics (gAGE), Universitat Politècnica de Catalunya (UPC), Barcelona, Spain

2 School of Information and Communication Technology (SoICT), Hanoi University of Science and Technology (HUST), Hanoi, Vietnam 